\title{
Сорбция прокаина и бупивакаина из водных растворов мембранами Nafion, модифицированными РEDOT
}

\author{
(C) 2020 Титова Т.С. ${ }^{1}$, Колганова Т.С. ${ }^{2}$, Паршина А.В. ${ }^{2}$, Бобрешова О.В. ${ }^{2}$ \\ ${ }^{1}$ Институт общей и неорганической химии им. Н.С. Курнакова Российской академии наук, Москва \\ ${ }^{2}$ Воронежский государственный университет, Воронеж
}

Поступила в редакцию 20.07.2020 г.

DOI: $10.17308 /$ sorpchrom.2020.20/2953

Местные анестетики прокаина (2-(диэтиламино)этил-4-аминобензоат) и бупивакаина ((RS)-1-Бутил-N-(2,6-диметилфенил)-пиперидин-2-карбоксамид) гидрохлориды широко используются в медицинской практике. Для их определения различными методами используют разнообразные сорбционные материалы. Ранее было показано, что введение поли-3,4-этилендиокситиофена (PEDOT) в перфторированные сульфокатионообменные мембраны Nafion позволяет снизить мешающее влияние ионов гидроксония на отклик сенсоров, аналитическим сигналом которых является потенциал Доннана (ПД), в растворах местных анестетиков. При этом модификация оказывает противоположное влияние на чувствительность ПД-сенсоров к катионам прокаина и бупивакаина. В этой связи исследование сорбционных свойств данных материалов в растворах местных анестетиков представляет интерес для дальнейшей оптимизации характеристик сенсоров.

Целью работы было исследование сорбции катионов прокаина и бупивакаина из их водных растворов мембранами Nafion-117, модифицированными PEDOT. Показано, что влагосодержание мембран Nafion-117 и Nafion-117+PEDOT, приведенных в равновесие с растворами местных анестетиков, снижается из-за присутствия объемных катионов с гидрофобными фрагментами в структуре, при этом замещение протонов на органические катионы ограничено стерическим фактором. Влагосодержание мембран, приведенных в равновесие с раствором $\mathrm{BupHCl,} \mathrm{снижается} \mathrm{в} \mathrm{1.4-1.8} \mathrm{раз} \mathrm{по} \mathrm{срав-}$ нению с таковым для образца в $\mathrm{H}^{+}$-форме, а концентрации сорбированных катионов бупивакаина и десорбированных протонов соизмеримы в пределах погрешности. Влагосодержание мембран, приведенных в равновесие с раствором ProHCI, снижается в 3.7-4.7 раз по сравнению с исходной, а концентрация десорбированных ионов гидроксония ниже, чем концентрация сорбированных ионов прокаина. Кроме того, возрастание концентрации PEDOT в мембране противоположно влияет на сорбцию прокаина и бупивакаина из водных растворов. Возможной причиной является различное расположение функциональных групп в структуре катионов, в результате которого катионы прокаина склонны к образованию димеров и мицелл в водных растворах, что способствует их сверхэквивалентной сорбции, тогда как для катионов бупивакаина это не свойственно.

Ключевые слова: перфторированные сульфокатионообменные мембраны, PEDOT, гибридные материалы, ионный обмен, сорбция, прокаин, бупивакаин.

\section{Введение}

Местные анестетики прокаина (2-(диэтиламино)этил-4-аминобензоат) и бупивакаина ((RS)-1-Бутил-N-(2,6-диметилфенил)-пиперидин-2-карбоксамид) гидрохлориды широко используются в медицинской практике. Для их определения различными методами используют разнообразные сорбционные материалы. В работе [1] обсуждается перспективность экстракционного и сорбционного концентрирования прокаина, лидокаина и ультракаина в виде ионных ассоциатов с хромогенными ор-

Tuтова и др. / Сорбционные и хроматографические процессы. 2020. Т. 20. № 4. С. 477-484 
ганическими реагентами в качестве пробоподготовки к фотометрическому, спектроскопическому и цветометрическому определению. Многократная твердофазная микроэкстракция прокаина и некоторых других лекарственных веществ на волокнах, покрытых полидиметилсилоксаном, предложена для подготовки проб к газохроматографическому анализу [2]. Сравнение хроматографических стационарных фаз на основе кремнезема и капиллярных монолитов, модифицированных сополимером метакриловой кислоты и этилендиметакрилата с молекулярными отпечатками бупивакаина, представлено в работе [3]. Также в работе [4] исследовано влияние плотности сшивания молекулярно импринтированных сополимеров метакриловой кислоты с этиленгликоль диметакрилатом и метилметакрилатом на распознавание бупивакаина. Новые ковалентные органические каркасы, модифицированные наночастицами оксида титана [5], и углеродные наносорбенты (магнитномодифицированные графен и углеродные нанотрубки (УНТ) с карбоксильными группами) [6] были синтезированы для извлечения местных анестетиков из плазмы крови человека для последующего их определения методом жидкостной хроматографии с массспектрометрическим детектированием.

При разработке электрохимических сенсоров для определения местных анестетиков могут быть использованы катионообменные мембраны (полиимидная мембрана [7], перфторированная сульфокатионообменная мембрана типа Nafion [8], пластифицированная поливинилхлоридная мембрана с ионной парой новокаинтетрафенилборат [9]) и гибридные материалы на их основе (композит полиамидосульфоновой кислоты и многостенных УНТ [10], мембраны типа Nafion, модифицированные наночастицами оксидов [11] и поли-3,4-этилендиокситиофеном (PEDOT) [12]). В работе [12] показано, что введение PEDOT в мембраны Nafion позволяет снизить мешающее влияние ионов гидроксония на отклик сенсоров, аналитическим сигналом которых является потенциал Доннана (ПД), в растворах прокаина, лидокаина и бупивакаина. При этом модификация оказывает противоположное влияние на чувствительность ПД-сенсоров к катионам прокаина и бупивакаина. В этой связи исследование сорбционных свойств данных материалов в растворах местных анестетиков представляет интерес для дальнейшей оптимизации характеристик сенсоров.

Целью работы было исследование сорбции катионов прокаина и бупивакаина из их водных растворов мембранами Nafion-117, модифицированными PEDOT.

\section{Экспериментальная часть}

Объекты исследования. Объектами исследования были выбраны гидрохлориды прокаина (ProHCI) и бупивакаина (BupHCI). Исследуемые растворы готовили растворением точных навесок сухих веществ ProHCI и BupHCI (OOO «СигмаАлдрич Рус», х.ч.) в бидистиллированной воде (удельное сопротивление 18 МОм·см). Значение $\mathrm{pH}$ раствора ProHCI составляло 5.64 \pm 0.03 , а раствора BupHCI $-5.12 \pm 0.02$, концентрация растворов составляла $0.01 \mathrm{M}$. В данных условиях прокаин и бупивокаин находятся преимущественно в форме однозарядных катионов (рис. 1). Значение концентрации исследуемых растворов было выбрано в соответствие с рабочим диапазоном концентраций ПД-сенсоров, для организации которых предназначены исследуемые мембраны [12].

Сорбентами являлись промышленная мембрана Nafion-117 (Sigma-Aldrich) и материалы на ее основе, содержащие PEDOT. Модификация мембран осуществлялась методом in situ окислительной полимеризации 3,4-этилендиокситиофена (мономер), варьируя концентрации и соотношение реагентов. Были исследованы образцы мембран, последовательно обработанные в течение 2 ч в растворе персульфата

Tитова и др. / Сорбционные и хроматографические процессы. 2020. Т. 20. № 4. С. 477-484 
аммония (окислителя), деионизированной воде и 0.002 или $0.01 \mathrm{M}$ растворе мономера в 0.1 М соляной кислоте. Далее в тексте концентрация 3,4-этилендиокситиофена и соотношение концентраций мономера и окислителя использованы в обозначении образцов. Методика получения мембран, а также их равновесные и транспортные свойства описаны в [12]. Исходные и модифицированные образцы были получены в лаборатории ионики функциональных материалов ИОНХ РАН (заведующий лабораторией - д.Х.н., проф., член.-корр. РАН Ярославцев А.Б., материалы синтезированы аспиранткой Юровой П.А.).

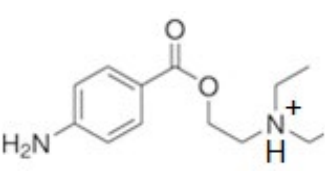

a

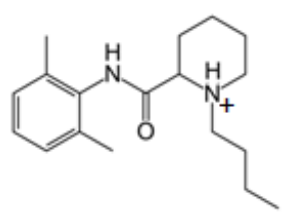

6

Рис. 1. Строение ионов $\mathrm{ProH}^{+}$(а) и $\mathrm{BupH}^{+}$(б)

Fig. 1. The structure of $\mathrm{ProH}^{+}$(a) and $\mathrm{BupH}^{+}$(b) ions

Методы исследования. До контакта с растворами местных анестетиков мембраны находились в $\mathrm{H}^{+}$-форме, для этого их выдерживали в $10 \%$-ном растворе $\mathrm{HCl}$ при комнатной температуре в течение суток, затем промывали в бидистиллированной воде до исчезновения реакции на $\mathrm{Cl}^{-}$-ионы.

Сорбцию прокаина или бупивакаина из их водных растворов мембранами Nafion-117 и Nafion-117+PEDOT исследовали в статических условиях методом ограниченного объема $\left(\mathrm{V}=50 \mathrm{~cm}^{3}, c=0.01 \mathrm{M}\right)$ при комнатной температуре. Концентрацию ионов, участвующих в ионном обмене, оценивали в расчете на единицу массы сухой мембраны для сопоставления с ионообменной емкостью (ИОЕ). Установление равновесия в системах контролировали потенциометрически с помощью высокоомного потенциометра, стеклянного электрода (ЭС-10601/4, ООО «Эконикс-эксперт») и хлоридсеребряного электрода сравнения (ЭСр10103, ООО «Эконикс-эксперт»). Значения $\mathrm{pH}$ внешнего раствора фиксировали каждые 24 ч до установления постоянного значения. Эксперимент дублировали не менее 3 раз. Концентрацию ионов гидроксония поступивших из мембраны в равновесный раствор $\left(c_{H_{3} O^{+}}\right.$, ммоль/г) рассчитывали по изменению $\mathrm{pH}$ внешнего раствора с учетом его объема раствора и массы сухого образца мембраны в исходной $\mathrm{H}^{+}$-форме:

$$
c_{\mathrm{H}_{3} \mathrm{O}^{+}}=\frac{\left(10^{-p H^{\prime}}-10^{-p H}\right) \cdot \mathrm{V}}{m},
$$

где $\mathrm{pH}$ - исходное значение $\mathrm{pH}$ внешнего раствора; $p H^{\prime}$ - значение $\mathrm{pH}$ равновесного раствора; $V$ - объем раствора, мл; $m$ - масса сухой мембраны в $\mathrm{H}^{+}$-форме, г.

Кроме того, устанавливали концентрацию ионов местных анестетиков и влагосодержание термогравиметрически с помощью Установки дифференциальнотермического и термогравиметрического анализа «Thermoscan-2». Перед высушиванием образцы мембран выдерживали в течение 6-8 ч в эксикаторе над насыщенным раствором $\mathrm{Na}_{2} \mathrm{HPO}_{4}$, обеспечивающем относительную влажность 95\%. Это было необходимо, поскольку погрешность оценки массы набухшей мембраны после непосредственного контакта с водными растворами возрастает. Высушивали мембраны нагреванием со скоростью 5 град/мин до температуры $105^{\circ} \mathrm{C}$. Температура нагрева не превышала температуру стеклования перфторполимера $\left(110^{\circ} \mathrm{C}\right)$ для обеспечения возможности дублирования эксперимента на одних и тех же образцах. Эксперимент дублировали не менее 3 раз. 
Концентрацию ионов прокаина $\left(c_{\mathrm{ProH}^{+}}\right.$, ммоль/г) или бупивакаина $\left(c_{B u p H^{+}}\right.$, ммоль/г), поступивших в фазу мембраны, устанавливали по разности масс сухого образца в $\mathrm{H}^{+}$-форме и сухого образца, приведенного в равновесие с раствором прокаина или бупивакаина, соответственно:

$$
c_{A^{+}}=\frac{\left(m^{\prime}-m\right) \cdot 1000}{M \cdot m},
$$

где $c_{A^{+}}$- концентрация ионов местного анестетика в фазе мембраны, ммоль/г; $m$ - масса сухой мембраны в $\mathrm{H}^{+}$-форме, г; $m^{\prime}$ - масса сухой мембраны, приведенной в равновесие с раствором местного анестетика, г; $\mathrm{M}$ - молярная масса местного анестетика, г/моль.

Влагосодержание $(w, \%)$ мембран устанавливали по разности масс сухого и набухшего образца, находящегося в $\mathrm{H}^{+}$-форме или приведенных в равновесие с раствором местного анестетика:

$$
w=\frac{\left(m^{\prime \prime}-m\right) \cdot 100}{m}
$$

где $m$ '” и $m$ - массы набухшей и сухой мембраны в одной и той же ионной форме, соответственно, г.

\section{Обсуждение результатов}

В работе [12] на основе анализа равновесных и транспортных характеристик мембран Nafion-117 и Nafion-117+PEDOT показано, что PEDOT располагается в гидрофильной фазе мембраны. Об этом свидетельствует равномерное окрашивание мембран по толщине, уменьшение ИОЕ с увеличением концентрации допанта (табл. 1), а также существенное возрастание проводимости модифицированных образцов в $\mathrm{H}^{+}$-форме [12]. При этом модификация мембран Nafion-117 поли-3,4-этилендиокситиофеном приводит к изменению влагосодержания материалов не более, чем на $1 \%$ [12]. Это обусловлено небольшим содержанием допанта в мембранах из-за невысокой концентрации анионов $\mathrm{S}_{2} \mathrm{O}_{8}{ }^{2-}$, поступающих в мембрану по необменному механизму при ее обработке персульфатом аммония, и соответственно невысокой концентрации мономера, которую они способны окислить.

Мембраны Nafion-117 и Nafion-117+PEDOT, приведенные в равновесие с растворами местных анестетиков, характеризуются существенным снижением влагосодержания по сравнению с образцами в $\mathrm{H}^{+}$-форме. Влагосодержание мембран, приведенных в равновесие с раствором ProHCI, снижается в 3.7-4.7 раз, а приведенных в равновесие с раствором ВuрНСІ - в 1.4-1.8 раза (табл. 1). Видимо, объемные органические катионы с гидрофобными фрагментами в структуре, располагаясь, как вблизи отрицательно заряженных фиксированных сульфогрупп мембраны, так и в центре пор, вытесняют из них «электронейтральный» раствор. Возможные причины более низких значений влагосодержания мембран после контакта с раствором ProHCI обсуждены далее.

После достижения равновесия в системах с мембранами на основе Nafion-117 и растворами $\mathrm{ProHCl}$ и $\mathrm{BupHCl}$ значения $\mathrm{pH}$ внешнего раствора снижаются от 5.61 и 5.15 до 3.42-3.74 и 3.02-3.70, соответственно. Учитывая значения константы диссоциации прокаина $(\mathrm{pK}=8.9)$ и бупивакаина $(\mathrm{pK}=8.1)$, в равновесном растворе, также как и в исходном, они находятся в форме однозарядных катионов. Тогда как возможность протолиза катионов $\mathrm{ProH}^{+}$и $\mathrm{BupH}^{+}$в фазе мембраны в $\mathrm{H}^{+}$-форме не исключена. 
Таблица 1. Отношение влагосодержания $(w)$ мембраны в $\mathrm{H}^{+}$-форме и приведенной в равновесие с раствором анестетика, концентрация ионов $\mathrm{H}_{3} \mathrm{O}^{+}, \mathrm{ProH}^{+}$и $\mathrm{BupH}^{+}$, поступивших в равновесный раствор $\left(c_{\mathrm{H}_{3} \mathrm{O}^{+}}\right)$и мембрану $\left(\mathrm{ProH}^{+}, c_{\mathrm{BupH}^{+}}\right)$

Table 1. The ratio of water uptake $(w)$ in the membrane in the $\mathrm{H}^{+}$-form being in equilibrium with the anesthetic solution, concentration of $\mathrm{H}_{3} \mathrm{O}^{+}, \mathrm{ProH}^{+}$and $\mathrm{BupH}^{+}$ions, introduced in the equilibrium solution $\left(c_{\mathrm{H}_{3} \mathrm{O}^{+}}\right)$and membrane $\left(\mathrm{CProH}^{+}, c_{\mathrm{BupH}^{+}}\right)$

\begin{tabular}{|c|c|c|c|c|c|}
\hline $\begin{array}{c}c_{\text {мономер }}, \mathrm{M}, \\
c_{\text {мономер }} / c_{\text {окислитель }}\end{array}$ & Немодиф. & $0.002,1 / 1.25$ & $0.002,1 / 2.5$ & $0.01,1 / 1.25$ & $0.01,1 / 2.5$ \\
\hline $\begin{array}{l}\text { ИОЕ, } \pm 0.01 \\
\text { ммоль/г [12] } \\
\end{array}$ & 0.65 & 0.63 & 0.63 & 0.61 & 0.59 \\
\hline$\frac{w_{H^{+}} \text {-форма }}{w_{H^{+} / \text {ProH }^{+} \text {-фopмa }}}$ & 3.7 & 3.9 & 3.9 & 4.7 & 3.9 \\
\hline$\frac{w_{H^{+}-\text {форма }}}{w_{H^{+} / \text {Вирн } H^{+}-\text {форма }}}$ & 1.6 & 1.7 & 1.7 & 1.4 & 1.8 \\
\hline $\begin{array}{c}c_{H_{3} O^{+}}, \text {ммоль/Г } \\
\text { (раствор ProHCl) }\end{array}$ & $\begin{array}{c}0.099 \pm \\
0.002\end{array}$ & $\begin{array}{c}0.0970 \pm \\
0.0016\end{array}$ & $\begin{array}{c}0.0888 \pm \\
0.0010\end{array}$ & $\begin{array}{c}0.181 \pm \\
0.004\end{array}$ & $\begin{array}{c}0.0843 \pm \\
0.0013 \\
\end{array}$ \\
\hline $\begin{array}{c}c_{\mathrm{H}_{3} \mathrm{O}^{+}}, \text {ммоль } / \Gamma \\
\text { (раствор BupHCl) }\end{array}$ & $\begin{array}{c}0.311 \pm \\
0.002\end{array}$ & $\begin{array}{c}0.2937 \pm \\
0.0006\end{array}$ & $\begin{array}{c}0.2957 \pm \\
0.0005\end{array}$ & $\begin{array}{c}0.0994 \pm \\
0.0004\end{array}$ & $\begin{array}{c}0.3069 \pm \\
0.0008\end{array}$ \\
\hline$c_{\text {ProH }^{+}}$, ммоль/Г & $\begin{array}{c}0.4377 \pm \\
0.0010\end{array}$ & $\begin{array}{c}0.4686 \pm \\
0.0005\end{array}$ & $\begin{array}{c}0.4664 \pm \\
0.0006\end{array}$ & $\begin{array}{c}0.4475 \pm \\
0.0010\end{array}$ & $\begin{array}{c}0.4540 \pm \\
0.0007\end{array}$ \\
\hline$c_{\text {BupH }^{+}}$, ммоль $/ \Gamma$ & $\begin{array}{c}0.2551 \pm \\
0.0006 \\
\end{array}$ & $\begin{array}{c}0.2517 \pm \\
0.0002 \\
\end{array}$ & $\begin{array}{c}0.2616 \pm \\
0.0004 \\
\end{array}$ & $\begin{array}{c}0.1251 \pm \\
0.0003 \\
\end{array}$ & $\begin{array}{c}0.2534 \pm \\
0.0004 \\
\end{array}$ \\
\hline
\end{tabular}

Получено, что значения концентрации ионов гидроксония, поступивших в раствор ProHCl, в 3 раза меньше, чем в раствор $\mathrm{BupHCl}$ (табл. 1). Исключение составляет образец, полученный обработкой 0.01 М раствором мономера с избытком окислителя $1 / 1.25$, для которого концентрация десорбированных ионов гидроксония в раствор ProHCl в 3 раза больше, чем в раствор $\mathrm{BupHCl}$ (табл. 1). При этом найденные термогравиметрически значения концентрации сорбированных ионов прокаина в 1.7 раз больше, чем значения концентрации сорбированных ионов бупивакаина (табл. 1). Это коррелирует с большим снижением влагосодержания мембран, контактирующих с растворами $\mathrm{ProHCl}$ (табл. 1). Также необходимо отметить, что как концентрация десорбированных ионов гидроксония, так и сорбированных ионов местных анестетиков ниже, чем ИОЕ мембран. Видимо, замещение протонов на объемные органические катионы ограничено стерическим фактором.

Таким образом, найденная потенциометрически концентрация ионов гидроксония, поступивших в раствор $\mathrm{BupHCl}$, и найденная термогравиметрически концентрация ионов бупивакаина, поступивших в мембраны, соизмеримы в пределах погрешности определения (табл. 1). Это свидетельствует о том, что сорбция бупивакаина осуществляется за счет ионного обмена, при котором один протон замещается одним катионом анестетика. В тоже время в поглощение ионов прокаина мембраной существенный вклад вносит сверхэквивалентная сорбция (0.267-0.378 ммоль/г). Это может быть обусловлено склонностью ионов прокаина к образованию димеров и мицелл в водных растворах подобно самоорганизации поверхностно активных веществ (рис. 2) [13-15]. Возможно, что взаимодействие димеров ионов прокаина одновременно с несколькими фиксированными сульфогруппами мембраны затруднительно, поэтому они ориентируются в центр пор, взаимодействуя одной из амино- 
групп с коионами. В связи с этим концентрация ионов прокаина в мембране оказывается выше, чем бупивакаина и влагосодержание мембран снижается в большей степени (табл. 1).

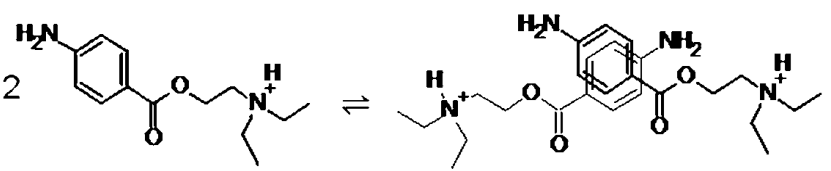

Рис. 2. Строение димеров ионов $\operatorname{ProH}^{+}$[13]

Fig. 2. The structure of the dimers of $\mathrm{ProH}^{+}$ions [13]

Влияние модификации мембран на влагосодержание и концентрацию сорбата наблюдается для образца, полученного обработкой $0.01 \mathrm{M}$ раствором мономера с избытком окислителя $1 / 1.25$, т.е. при относительно высокой концентрации PEDOT в мембране. Более высокое влагосодержание и низкая концентрация ионов бупивакаина для данного образца по сравнению с другими модифицированными образцами (табл. 1) может быть обусловлена формированием водородных связей между протоноакцепторной серой поли-3,4-этилендиокситиофена и сульфогруппами мембраны, исключающих часть протонов из ионного обмена. Это согласуется с более низким значением ИОЕ для образцов с большей концентрацией допанта. Однако для данного образца возрастает доля ионов прокаина, сорбированных посредством ионного обмена, и влагосодержание снижается. Видимо, присутствие в порах допанта с $\pi$ - $\pi$-сопряжением влияет на формирование и ориентацию димеров и мицелл прокаина, способствуя взамодействию дополнительного числа ионов прокаина с сульфогруппами мембраны.

\section{Заключение}

Исследовано влияние природы сорбата и состава материалов на основе мембран Nafion-117 и поли-3,4-этилендиокситиофена на влагосодержание материалов и особенности сорбции катионов прокаина и бупивакаина из их водных растворов. Влагосодержание мембран Nafion-117 и Nafion-117+PEDOT, приведенных в равновесие с растворами местных анестетиков, снижается из-за присутствия объемных катионов с гидрофобными фрагментами в структуре, при этом замещение протонов на органические катионы ограничено стерическим фактором. Возрастание концентрации PEDOT в мембране противоположно влияет на сорбцию прокаина и бупивакаина из водных растворов. Возможной причиной является различное расположение функциональных групп в структуре катионов, в результате которого катионы прокаина склонны к образованию димеров и мицелл в водных растворах, что способствует их сверхэквивалентной сорбции, тогда как для катионов бупивакаина это не свойственно.

Исследование выполнено при финансовой поддержке РФФИ в рамках научного проекта № 19-38-60045 (The reported study was funded by RFBR, project number 19-38-60045).

\section{Список литературы}

1. Адамова Е.М., Иванов В.М. // Журнал аналитической химии. 2016. Т. 71. № 12. С. 1250-1262. DOI: $10.7868 / \mathrm{S} 0044450216120021$.
2. Koster E.H.M., Niemeijer I.S., De Jong G.J. // Chromatographia. 2002. Vol. 55. No 1-2. pp. 69-73. DOI: $10.1007 / \mathrm{BF} 02492317$. 
3. Oxelbark J, Legido-Quigley C., Aureliano C.S.A., Titirici M.M. et al. // Journal of Chromatography A. 2007. Vol. 1160. No 1-2. pp. 215-226. DOI: 10.1016/j.chroma.2007.05.057.

4. Golker K., Nicholls I.A. // European Polymer Journal. 2016. Vol. 75. pp. 423-430. DOI: 10.1016/j.eurpolymj.2016.01.008.

5. Zhao L.M., Gan L., Zhang Y. // Journal of Chromatography B. 2019. Vol. 1130. pp. 121831. DOI: 10.1016/j.jchromb.2019.121831.

6. Ma J.B., Zhao L.M., Rui Q.H., Liao Y.F. et al. // Analytica chimica acta. 2017. Vol. 960. pp. 72-80. DOI: 10.1016/j.aca.2017.01.033.

7. Güngör Ö., Özcan İ., Erdoğan M.A., Ateş B. et al. // Analytical Letters. 2020. Vol. 53. No 2. pp. 228-244. DOI: 10.1080/00032719.2019. 1646752.

8. Li N., Duan J., Chen G. // Analytical sciences. 2003. Vol. 19. No 12. pp. 1587-1592. DOI: 10.2116 /analsci.19.1587.

9. Кулапина Е.Г., Баринова О.В. // Журнал аналитической химии. 2001. Т. 56. № 5. C. 518-522.

10. Zhang X., Zhao D., Feng L., Jia L. et al.
// Microchimica Acta. 2010. Vol. 169. No 1-2. pp. 153-159. DOI: 10.1007/s00604-010-0330-4.

11. Паршина А.В., Денисова Т.С., Сафронова Е.Ю., Бобрешова О.В. и др. // Российские нанотехнологии. 2015. Т. 10. № 9-10. С. 66-72.

12. Титова Т.С., Юрова П.А., Колганова Т.С., Стенина И.А. и др. // Журнал аналитической химии. 2020. Т. 75. № 8. С. 750-759. DOI: $10.31857 / \mathrm{S} 0044450220080162$.

13. Shaikh V.R., Dagade D.H., Terdale S.S., Hundiwale D.G. et al. // Journal of Chemical \& Engineering Data. 2012. Vol. 57. No 11. pp. 3114-3122. DOI: dx.doi.org/ 10.1021/je3006985.

14. Shaikh V.R., Dagade D.H., Hundiwale D.G, Patil K.J. // Journal of Molecular Liquids. 2011. Vol. 164. No 3. pp. 239-242. DOI: 10.1016/j.molliq.2011.09.024.

15. Zhang J., Dong B., Zheng L., Li G. // Colloids and Surfaces A: Physicochemical and Engineering Aspects. 2006. Vol. 290. No 1-3. pp. 157-163. DOI: 10.1016/j.colsurfa. 2006.05.019.

\title{
The sorption of procaine and bupivacaine from aqueous solutions by Nafion membranes modified with PEDOT
}

\author{
(C) 2020 Titova T.S. ${ }^{1}$, Kolganova T.S. ${ }^{2}$, Parshina A.V. ${ }^{2}$, Bobreshova O.V. ${ }^{2}$ \\ ${ }^{1}$ Kurnakov Institute of General and Inorganic Chemistry of the Russian Academy of Sciences, Moscow \\ ${ }^{2}$ Voronezh State University, Voronezh
}

Local anesthetics, procaine (2-(diethylamino)ethyl-4-aminobenzoate) and bupivacaine ((RS)-1Butyl-N-(2,6-dimethylphenyl)-pyridine-2-carboxamide) hydrochloride are widely used in medicine. Various sorption materials and methods are used for their identification. It was demonstrated earlier that the introduction of poly(3,4-ethylenedioxythiophene) (PEDOT) to Nafion perfluorosulfonic acid cation exchange membranes reduced the interfering effect of hydroxonium ions on the response of Dp-sensors in local anesthetics solutions. The modification has an opposite effect on the sensitivity of PD-sensors to cations of procaine and bupivacaine. It is therefore important to study the sorption properties of these materials in local anesthetics solutions for further optimisation of the sensors' characteristics.

The aim of our research was to study the sorption of procaine and bupivacaine cations from aqueous solutions byNafion-117 membranes modified with PEDOT. The study demonstrated that the moisture content in Nafion-117 and Nafion-117+PEDOT membranes in equilibrium with the local anesthetics solutions decreases due to the presence of three-dimensional cations with hydrophobic fragments. The substitution of protons with organic cations is limited by the steric factor. The moisture content of membranes in equilibrium with a BupHCl reduces by 1.4-1.8 times as compared to the sample in the $\mathrm{H}^{+}$form. Concentrations of the absorbed procaine cations and desorbed protons are compatible within the measure of inaccuracy. The moisture content of membranes in equilibrium with a ProHCI solution reduces by 3.7-4.7 times as compared to the initial. The concentration of desorbed hydroxonium ions is lower than the concentration of absorbed procaine ions. Furthermore, the growth of the concentration of PEDOT in the membrane has the opposite effect on the sorption of procaine and bupivacaine from aqueous solutions. A possible cause of such an interaction between the ions of local anesthetics and membranes (including the ones containing a dopant with $\pi-\pi$ conjugation) is the location of the functional groups in the cation structure. As a result, procaine cations tend to form dimers and micelles in aqueous solutions, while bupivacaine cations do not have this feature.

Keywords: perfluorosulfonic acid cation exchange membranes, PEDOT, hybrid materials, ion exchange, sorption, procaine, bupivacaine. 


\section{References}

1. Adamova E.M., Ivanov V.M., Journal of Analytical Chemistry, 2016, Vol. 71, No 12, pp. 1169-1181. DOI: 10.1134/S1061934816120029.

2. Koster E.H.M., Niemeijer I.S., De Jong G.J., Chromatographia, 2002, Vol. 55, No 1-2, pp. 69-73. DOI: $10.1007 / \mathrm{BF} 02492317$.

3. Oxelbark J., Legido-Quigley C., Aureliano C.S.A., Titirici M.M. et al., Journal of Chromatography $A$, 2007, Vol. 1160, No 1-2, pp. 215-226. DOI: 10.1016/j.chroma.2007.05.057.

4. Golker K., Nicholls I.A., European Polymer Journal, 2016, Vol. 75, pp. 423-430. DOI: 10.1016/j.eurpolymj.2016.01.008.

5. Zhao L.M., Gan L., Zhang Y., Journal of Chromatography B, 2019, Vol. 1130, pp. 121831. DOI: 10.1016/j.jchromb.2019.121831.

6. Ma J.B., Zhao L.M., Rui Q.H., Liao Y.F. et al., Analytica chimica acta, 2017, Vol. 960, pp. 72-80. DOI: 10.1016/j.aca.2017.01.033.

7. Güngör Ö., Özcan İ., Erdoğan M.A., Ateş B. et al., Analytical Letters, 2020, Vol. 53, No 2, pp. 228-244. DOI: 10.1080/00032719.2019.1646752.

8. Li N., Duan J., Chen G., Analytical sciences, 2003, Vol. 19, No 12, pp. 1587-1592. DOI: 10.2116/analsci.19.1587.

9. Kulapina E.G., Barinova O.V., Journal of Analytical Chemistry, 2001, Vol. 56, No 5, pp. 457-460. DOI: 10.1023/A:1016683121191.

Титова Татьяна Сергеевна - к.х.н., научный сотрудник, лаборатория ионики функциональных материалов, Институт общей и неорганической химии имени Н.С. Курнакова РАН, Москва

Колганова Татьяна Сергеевна - к.Х.н., преподаватель, кафедра аналитической химии, Воронежский государственный университет, Воронеж

Паршина Анна Валерьевна - д.х.н., доцент, кафедра аналитической химии, Воронежский государственный университет, Воронеж

Бобрешова Ольга Владимировна - д.Х.н., профессор, главный научный сотрудник, кафедра аналитической химии, Воронежский государственный университет, Воронеж
10. Zhang X., Zhao D., Feng L., Jia L. et al., Microchimica Acta, 2010, Vol. 169, No 1-2, pp. 153-159. DOI: 10.1007/s00604-010-0330-4.

11. Parshina A.V., Denisova T.S., Safronova E.Y., Bobreshova O.V. et al., Nanotechnologies in Russia, 2015, Vol. 10, No 9-10, pp. 748756. DOI: 10.1134/S199507801505016X.

12. Titova T.S., Yurova P.A., Kolganova T.S., Stenina I.A. et al., Journal of Analytical Chemistry, 2020, Vol. 75, No 10, pp. 1072-1079. DOI: $10.1134 / \mathrm{S} 106193482008016 \mathrm{X}$.

13. Shaikh V.R., Dagade D.H., Terdale S.S., Hundiwale D.G. et al., Journal of Chemical \& Engineering Data, 2012, Vol. 57, No 11, pp. 3114-3122.

DOI: dx.doi.org/10.1021/je3006985.

14. Shaikh V.R., Dagade D.H., Hundiwale D.G., Patil K.J., Journal of Molecular Liquids, 2011, Vol. 164, No 3, pp. 239-242. DOI: 10.1016/j.molliq.2011.09.024.

15. Zhang J., Dong B., Zheng L., Li G., Colloids and Surfaces A: Physicochemical and Engineering Aspects, 2006, Vol. 290, No 1-3, pp. 157-163. DOI: 10.1016/j.colsurfa. 2006.05.019.

Titova Tatyana S. - PhD in Chemistry, researcher, Laboratory of Ionics of Functional Materials, Kurnakov Institute of General and Inorganic Chemistry RAS, Moscow

Kolganova Tatyana S. - PhD in Chemistry, lecturer, Department of Analytical Chemistry, Voronezh State University, Voronezh

Parshina Anna V. - Doctor of Chemical Sciences, docent, Department of Analytical Chemistry, Voronezh State University, Voronezh, parshina ann@mail.ru

Bobreshova Olga V. - Doctor of Chemical Sciences, professor, chief researcher, Department of Analytical Chemistry, Voronezh State University, Voronezh 